\title{
The effects of potassium supplements, spironolactone or amiloride on the potassium status of patients with heart failure
}

\author{
C. DAVIDSON \\ M.A., M.B., M.R.C.P.

\begin{abstract}
Summary
Extra potassium supplements, spironolactone or amiloride were given for 5 months to forty-nine patients with heart failure who were taking furosemide and were in a steady state. Plasma potassium increased with all three treatments but there was no significant increase in total body potassium or red cell potassium. These findings together with other studies suggest that patients with heart failure taking diuretics do not have a significant depletion of body potassium.
\end{abstract}

L. BURKINSHAW

B.Sc., Ph.D.

\author{
D. B. MORGaN \\ M.D., M.R.C.Path.
}

Departments of Medicine, Medical Physics and Chemical Pathology, General Infirmary, Leeds

\section{Introduction}

Potassium depletion is generally accepted as one of the hazards of long-term treatment with potent diuretics in patients with heart failure, and these patients are therefore usually also given either potassium supplements or one of the potassiumsparing diuretics. The authors recently measured the total body potassium (TBK) of patients with chronic heart disease with a total body radiation counter (Davidson et al., 1976). The TBK in the patients with heart disease was not significantly different from the TBK in a group of healthy subjects. Moreover, among the patients with heart disease there was no difference between those who were taking diuretics and those who were not, and in those on diuretics there was no difference between those taking small doses of potassium supplements and those taking large doses.

These findings contrasted with previous reports in the literature, and did not support the view that potassium depletion was a complication of long-term diuretic therapy. Nevertheless, it could be argued that a cross-sectional study is an insensitive approach since it depends on the comparison of a group of patients with a group of controls; a more sensitive approach would be to study serial changes in individual patients. Ideally such a study should be carried out from the time the patients start diuretics

Address for reprint requests: Professor D. B. Morgan, Department of Chemical Pathology, The General Infirmary, Leeds. but this is difficult logistically and as far as the authors know it has not been done. Alternatively one can attempt to correct any deficit in body potassium in patients already established on treatment by giving extra potassium supplements or a potassium-retaining diuretic. If potassium depletion is present, these changes in treatment should cause an increase in $T B K$, even in a patient whose $T B K$ is reduced but still lies within the normal range. Surprisingly this approach has only rarely been used in heart failure (De Deuchaisnes, Busset and Collet, 1961; White, 1970; Davidson and Gillebrand, 1973).

A group of patients with heart failure have been studied who had been taking a constant dose of furosemide and potassium supplements for at least 6 months. The potassium supplements were either increased to $48 \mathrm{mmol} /$ day or replaced by spironolactone or amiloride. The dose of furosemide was kept constant throughout the study. The potassium status of the three treatment groups was assessed at monthly intervals for 5 months after the change of treatment.

\section{Patients}

The patients in this study came from a larger cross-sectional study of patients with heart failure (Davidson et al., 1976). Sixty-six patients who agreed to join the study were allocated to one of three treatment groups using random tables. Six patients were subsequently excluded from the potassium group because they were already taking $48 \mathrm{mmol}$ of potassium or more per day. Eleven patients did not finish the trial; six required an increased dose of diuretic, three defaulted and two died from myocardial infarction. The final analysis was therefore based on a total of forty-nine patients; thirteen patients had their potassium supplements increased to $48 \mathrm{mmol} / \mathrm{day}$; sixteen took spironolactone $(100 \mathrm{mg} /$ day $)$ and twenty took amiloride $(20 \mathrm{mg} /$ day $)$. The patients in the spironolactone and amiloride groups stopped their potassium supplements. The increase in potassium supplements in 
the potassium group (given Slow K) was on average $25 \mathrm{mmol} /$ day (range $8-40 \mathrm{mmol} /$ day). Clinical details of the patients are shown in Table 1 .

The patients were seen at least once, but usually twice, before their treatment was changed and then five times at monthly intervals. At each visit the patients were asked about symptoms and the side effects of treatment, and their TBK, plasma potassium, red cell potassium and 24-hr urine potassium excretion were measured. Details of these techniques are given elsewhere (Davidson et al., 1976). Chest $\mathrm{X}$-rays were taken at the beginning and end of the study. The total duration of the study was 18 months.

\section{Results}

Table 2 shows that the plasma, electrolytes, urea and creatinine were the same on average in the three groups before treatment was changed. The average TBK differed between the groups, but there were also differences in age and weight. The observed TBK was compared with the TBK predicted from sex, age, weight, height and skin fold thicknesses (Davidson et al., 1976). There was a small apparent deficit of TBK in each group $(205,79$ and $183 \mathrm{mmol}$ respectively).

None of the patients had any clinical or radiological deterioration during the study. Twelve patients (two on potassium supplements, three on spironolactone, seven on amiloride) had transient epigastric discomfort or nausea when they changed treatment. In three patients (two spironolactone, one amiloride) these symptoms persisted until the end of the study. Two patients in the spironolactone group had persistent gynaecomastia.

Figure 1 shows the changes in plasma potassium, urinary potassium excretion and TBK in the three groups of patients. The results have been calculated as the difference from the mean value before the treatment was changed. Plasma potassium increased at first in all groups by $0.1-0.2 \mathrm{mmol} / 1$ but the rise was not sustained in the potassium group. Urinary potassium excretion increased by the expected 20 $\mathrm{mmol} /$ day in the potassium group and decreased by the same amount in the other two groups who stopped their potassium supplements when they changed treatment. There were no significant changes in TBK.

In order to summarize the changes in the other measurements, the values before treatment have been compared with the values at the fourth month of treatment; the values at 4 months were representative of the values in the latter part of the study. There were small falls in body weight and blood pressure; the fall in weight was significant only in the potassium group $(P<0.05)$, and the fall in blood pressure was significant only in the spironolactone
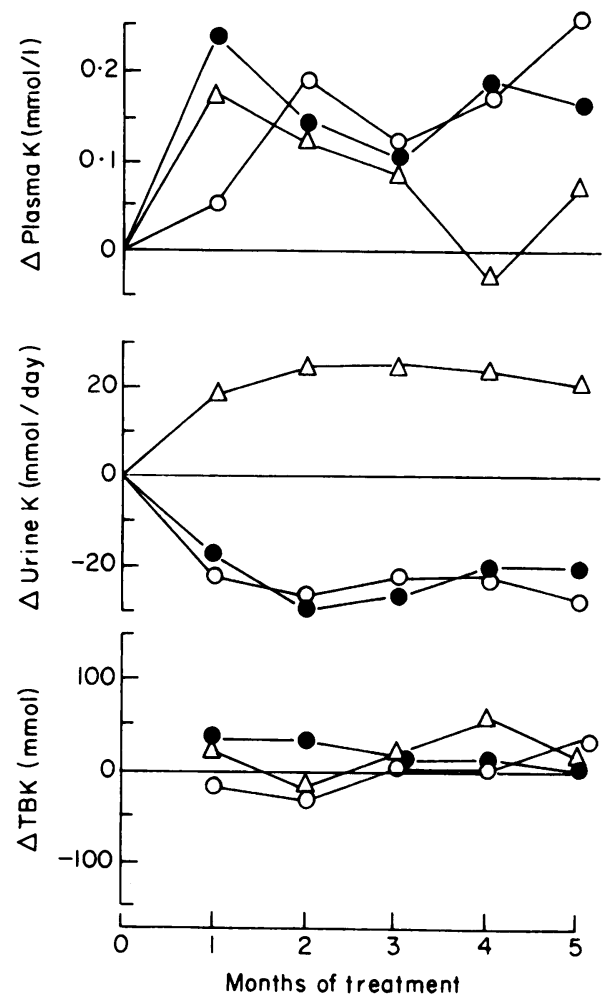

FIG. 1. The changes in plasma potassium, urinary potassium and total body potassium (TBK) in the three groups of patients. Results calculated as the difference from the mean value before the treatment was changed: $\triangle$ - patients given potassium supplements. $\bigcirc-$ patients given spironolactone. - patients given amiloride.

group $(P<0.001)$. There was a significant fall in plasma sodium $(P<0.001)$ and a rise in bicarbonate $(P<0.01)$ in the spironolactone group. There was a rise in blood urea in the amiloride group $(P<0 \cdot 01)$ but no significant change in the plasma creatinine. Red cell potassium did not change in any group.

\section{Discussion}

This longitudinal study was undertaken because the previous cross-sectional study of patients with heart failure had failed to detect large potassium deficits and was therefore at variance with numerous previous reports (Davidson et al., 1976). The patients in the present study had apparent deficits which were similar to those in the previous study $(50-200$ $\mathrm{mmol}$ ). However, extra potassium, spironolactone or amiloride failed to raise the total body or red cell $\mathrm{K}$ despite a rise in plasma potassium, which makes it unlikely they were potassium depleted.

There have been several similar studies in heart failure in which either extra potassium or a potassium-sparing diuretic has been added to the diuretic 


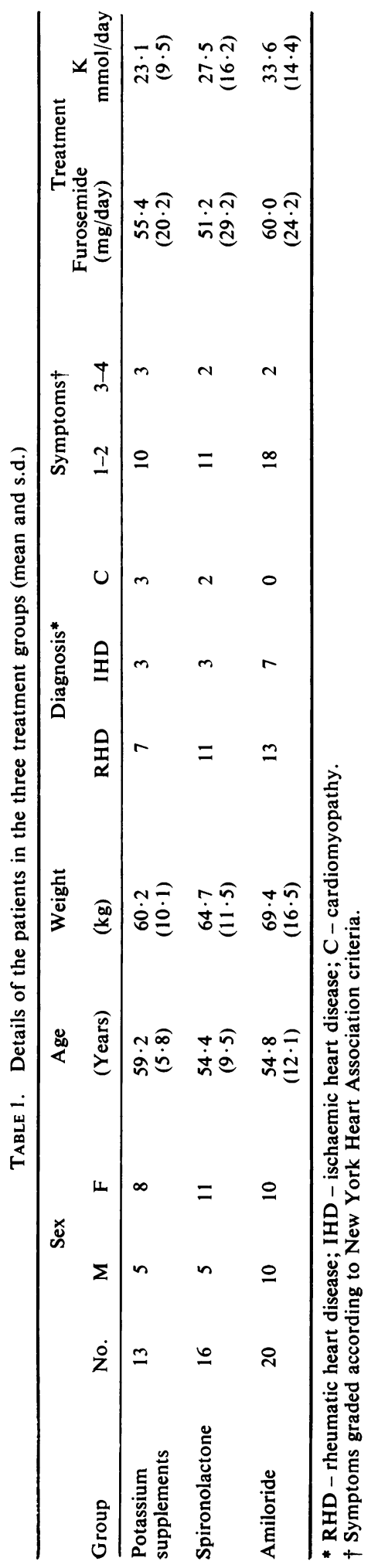




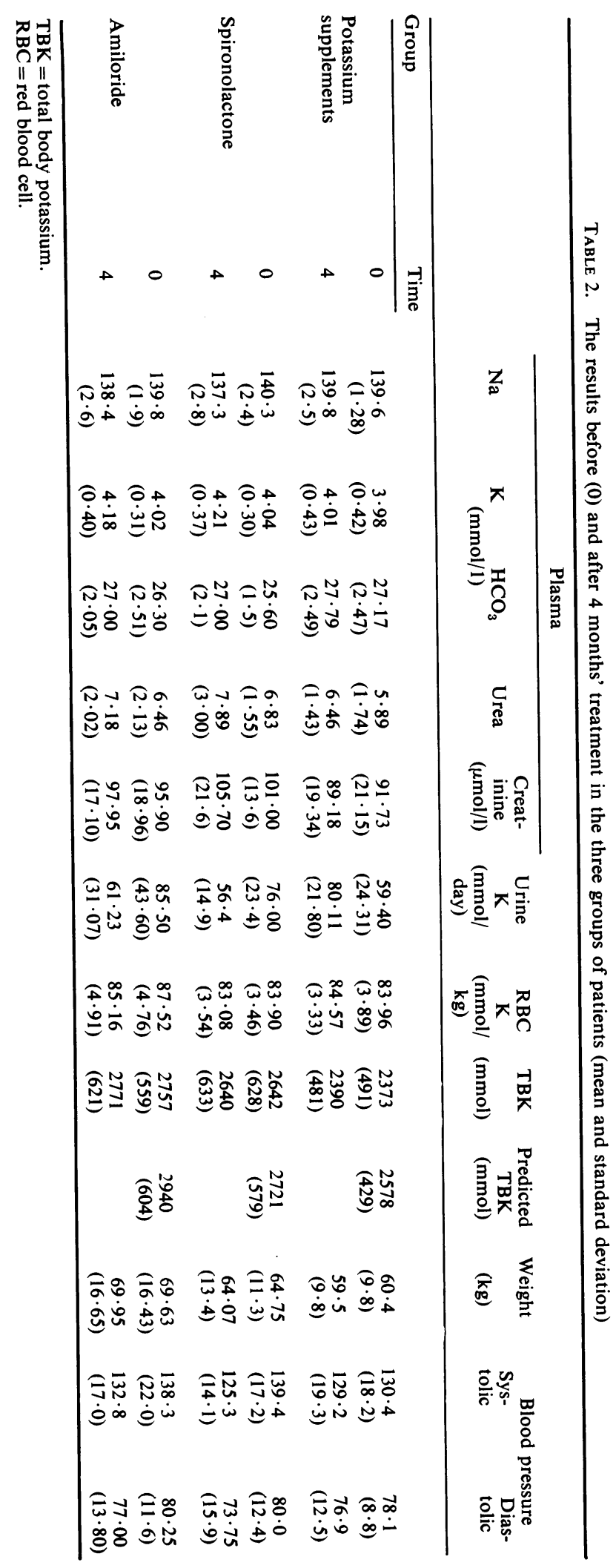


regime. Most studies have used exchangeable potassium $\left(\mathrm{K}_{\mathrm{e}}\right)$ as a measure of body potassium. They have often involved small numbers of patients followed for relatively short periods, and the results have been conflicting.

Three groups have studied the effect of potassium supplements. De Deuchaisnes et al. (1961) gave eight patients $40-120 \mathrm{mmol} /$ day of extra potassium for one to three weeks. The average $K_{e}$ did not change and the extra potassium was excreted in the urine. White (1970) gave seven patients with heart failure and an apparent potassium deficit $48 \mathrm{mmol} /$ day of extra potassium for 4 weeks. There was no change in plasma potassium but $\mathrm{K}_{\mathrm{e}}$ increased by an average of $200 \mathrm{mmol}$. Down, Polak and Rao (1972) gave four patients with heart failure and an apparent potassium deficit $48 \mathrm{mmol} /$ day for 2 months. There was no change in plasma potassium or $\mathrm{K}_{\mathrm{e}}$.

The results from studies of potassium-sparing diuretics have been equally inconclusive. Davidson and Gillebrand (1973) gave amiloride for 6 months to twenty-four patients with heart failure stabilized on furosemide. There was a sustained rise in plasma potassium; $\mathrm{K}_{\mathrm{e}}$ initially rose by $320 \mathrm{mmol}$ but at 6 months was no greater than before the change in treatment. Nicholls, Espiner and Hughes (1976) studied eleven patients with heart failure for 2 months after substituting amiloride for potassium supplements. There was no change in plasma potassium or $\mathrm{K}_{\mathrm{e}}$. White (1969) reported that spironolactone prevented any fall in $\mathrm{K}_{\mathbf{e}}$ in patients taking furosemide; Friis (1972) concluded that it did not increase $\mathrm{K}_{e}$ in patients with heart failure. There are several studies showing that spironolactone increases plasma potassium(George, Breckenridge and Dollery, 1973).

The present study is thus in agreement with most reports from the literature. Extra potassium supplements or potassium-sparing diuretics can increase plasma potassium, but they do not influence body potassium. These drugs may therefore be unnecessary to maintain body potassium in heart failure during long-term diuretic treatment. Lawson Boddy and Gray (1976) gave twenty-one patients with heart failure diuretics but no potassium supplements for a year. There was a small fall in plasma potassium but no change in TBK.

Nevertheless, the general view is that patients with heart failure are depleted of potassium and that the depletion is related to the use of potent diuretics (Leading Article, 1977). This view seems to be based on the numerous reports of low $\mathrm{K}_{e}$ in patients with heart failure taking diuretics and the demonstration that these diuretics can increase the urine potassium and lower the plasma potassium. The authors have recently reviewed all published data on exchangeable potassium in patients with heart disease (Morgan, Burkinshaw and Davidson, 1978). Although there was an apparent deficit of $20-30 \%$ of body potassium, this deficit was no greater in the patients taking diuretics than in those who were not, and could be explained by the muscle wasting which happens in chronic heart disease.

The findings in the present study, the authors' previous study (Davidson et al., 1976), the study of Lawson et al. (1976) and the authors' review of the literature (Morgan et al., 1978) lead the authors to conclude that there is no true potassium depletion in patients with heart disease, even those taking diuretics. The only reason for treating patients with potassium supplements or potassium-sparing agents is to prevent or treat a low plasma potassium.

\section{Acknowledgments}

We are grateful to Dr W. Whitaker, Dr D. Smith and Mr M. Ionescu who allowed us to study their patients; Mrs D. Davidson who had a major responsibility in the organization of the study; Miss D. W. Krupowicz who made the TBK measurements; and Miss S. Hassam and the many staff of the Departments of Chemical Pathology who made the chemical measurements. The study was supported in part by a grant from G. D. Searle.

\section{References}

Davidson, C. \& Gillebrand, I.M. (1973) Use of amiloride as a potassium conserving agent in severe cardiac disease. British Heart Journal, 35, 456.

Davidson, C., Mclachlan, M.S.F., Burkinshaw, L. \& MorGaN, D.B. (1976) Effect of long-term diuretic treatment on body-potassium in heart disease. Lancet, i, 1044.

De Deuchaisnes, C.N., Busset, R. \& Collet, R.A. (1961) Exchangeable potassium in wasting, amyotrophy, heart disease, and cirrhosis of the liver. Lancet, ii, 681 .

Down, P.F., Polak, A. \& Rao, R. (1972) Fate of potassium supplements in six outpatients receiving long-term diuretics for oedematous disease. Lancet, ii, 721.

FRIIS, TH. (1972) In: Extrarenal Activity of Aldosterone and its Antagonists Excerpta Medica, Amsterdam, 35.

George, C.F., Breckenridge, A.M. \& Dollery, C.T. (1973) Comparison of the potassium-retaining effects of amiloride and spironolactone in hypertensive patients with thiazide-induced hypokalaemia. Lancet, ii, 1288.

Lawson, D.H., Boddy, K. \& Gray, J.M.B. (1976) Potassium supplements in patients receiving long-term diuretics for oedema. Quarterly Journal of Medicine, 45, 469.

LEADING ARTICLE (1977) Potassium in heart failure. British Medical Journal, 1, 469.

Morgan, D.B., Burkinshaw, L. \& Davidson, C. (1978) Potassium depletion in heart failure and its relation to long-term treatment with diuretics: a review of the literature. Postgraduate Medical Journal, 54, 72.

Nicholls, M.G., Espiner, E.A. \& Hughes, H. (1976) Effect of potassium-sparing diuretics on the renin-angiotensin-aldosterone system and potassium retention in heart failure. British Heart Journal, 38, 1025.

WhITE, R.J. (1969) The body electrolytes in heart failure and in systematic hypertension. M.D. thesis, University of Cambridge.

WhIte, R.J. (1970) Effect of potassium supplements on the exchangeable potassium in chronic heart disease. British Medical Journal, 3, 141. 